Teoria das ciências humanas 


\title{
Patologia e regras metodológicas
}

\author{
JOSÉ JEREMIAS DE OLIVEIRA FILHO
}

A METODOLOGIA DAS ciências sociais apresenta algumas dificuldades que não são exclusivas de determinadas correntes, mas estão presentes em todas elas, sejam analíticas, hermenêuticas ou dialéticas. Estas patologias metodológicas são o ecletismo, o reducionismo e o dualismo. Uma solução para tais dificuldades será a adoção dopluralismo metodológico. Max Weber tornou-se o ancestral clássico desta posição ao situar a investigação científica das ações humanas entre o positivismo e o historicismo do seu tempo, criticando, deste modo, as posturas exclusivas e restritivas ao desenvolvimento das ciências sociais e adotando um kantiano Mittelweg. Kaufmann dará continuidade a esta postura metodológica, situando a meio caminho entre o empirismo lógico do Círculo Viena e a fenomenologia de Husserl a possibilidade da ciência da sociedade e, mais tarde, em 1944, em um segundo livro de mesmo título, Metodologia das Ciências Sociais, acrescentando ao seu arsenal metodológico o pragmatismo norte-americano. Recentemente, Apel retomou o programa weberiano, desta vez, incorporando ao debate e ao diálogo metodológicos a hermenêutica heideggeriana, a filosofia da linguagem wittgensteiniana e o pragmatismo de Peirce em um cenário clássico de filosofia transcendental alemã.

O ecletismo como patologia metodológica pode ser definido pelo uso de conceitos fora dos seus respectivos esquemas conceituais e sistemas teóricos, alterando os seus significados. A ocorrência do termo sem definição que reduzisse ou eliminasse a sua ambigüidade, não permitiria saber a qual de vários conceitos possíveis está associado. Inadvertidamente, muitas vezes, utiliza-se o sinal que expressa o conceito, mas não o próprio conceito. $O$ discurso torna-se vazio ou obscuro sem que o cientista social perceba que a sua linguagem pode dificultar a comunicação. Se tal ocorrência é grave ao nível da teoria, será gravíssima em nível metateórico ou meta-sociológico. Neste caso os conceitos metodológicos desprovidos de suas características limitar-se-ão a nomeaçôes e classificaçôes rituais de posturas sem qualquer influência nas estratégias de investigação, o que é comum em textos produzidos por autores desprovidos de treinamento metateórico. Termos vazios de significado não podem funcionar como instrumental de reconstrução teórica ou metodológica. Esta é uma caracterização, diremos que, formal do ecletismo. 
Uma segunda ocorrência desta patologia consiste em dar uma funçăo teórica a expressōes descritivas ou em dar uma função descritiva a expressóes teóricas. Trata-se de uma das consequiências do uso inadequado dos conceitos anteriormente mencionados, pois o uso de nomes de termos conceitualmente vazios impede-nos de classificar as expressões lingüísticas de modo adequado e os níveis descritivo e teórico podem ser alternados inadvertidamente.

Além destas dificuldades estruturais, o ecletismo impede que o autor adote claramente uma postura teórico-metodológica, a partir da qual possa incorporar outras contribuições conceituais, tipológicas, classificicatórias ou teóricas em sentido forte, tendo grande dificuldade em apreender diferenças entre posições adotadas por autores e escolas com respeito às estratégias gerais de investigação. A grande dificuldade do ecletismo é, finalmente, a sua esterilidade intelectual explicitada por uma retórica vazia, seguida de impossibilidade crítica para o diálogo e a controvérsia conseqüente entre os enfoques sociológicos e metodológicos.

Não podemos esquecer algumas consideraçóes pragmáticas do problema que estamos analisando. E totalmente infundado, pelo que vimos, associar ecletismo com pluralismo e, quando isto ocorre, muitas vezes é indicativo da presença de um interlocutor dogmático tentando desqualificar o suposto adversário, desviando-se do diálogo intelectual. A esta definição negativa podemos acreścentar uma positiva. É quando se está preservando um sistema argumentativo, ainda rudimentar, para que se desenvolva até poder interagir de modo conseqüente com outro sistema mais desenvolvido e complexo. A adoção do pluralismo metodológico evitará os impasses do falso dilema - adotar-se o ecletismo ou o dogmatismo.

O reducionismose apresenta de várias formas, e a mais facilmente detectável é a naturalista. Consiste em adotar procedimentos das ciências naturais como modelo para as ciências sociais, por exemplo, os da física ou da biologia. As correntes positivistas desde o século passado têm adotado tal naturalismo. $\mathrm{O}$ empirismo lógico ao defender a tese da unidade metodológica das ciências empíricas foi claríssimo a respeito. Podemos citar nesta linha as obras de Neurath, Lundberg, Hempel, Nagel, Rudner, Brodbeck compartilhando a mesma tese. Em outro sentido, que pode atribuir-se a Quine originalmente, utilizamos hoje a expressão epistemologia naturalizada, para caracterizar investigaçóes epistemológicas que consultam resultados e procedimentos das ciências empíricas, em oposição a uma epistemologia normativista a priori; mas aqui também poderíamos situar a contribuição, por exemplo, da sociologia dos sistemas simbólicos, através das investigações a respeito da natureza social do conhecimento, a da sociologia da ciência etc. Foi, entretanto, o primeiro sentido já aludido de naturalismo que teve curso na metodologia das ciências sociais. Podemos concluir, de modo amplo, dizendo que o reducionismo quebra a identidade de uma disciplina 
científica ao rebatê-la acriticamente sob outra disciplina, seja ela empírica ou formal. E uma nova caracterização da noção de regra metodológica, compatível com o pluralismo metodológico apresenta uma solução para esta dificuldade, o que discutiremos mais adiante.

Outras manifestações peculiares de reducionismo ocorrerão nas abordagens dialética e hermenêutica. Engels é exemplo de autor que defende a unidade metodológica das ciências fora da postura analítica do empirismo lógico. Aqueles que buscam caracterizar uma hermenêutica das ciências naturais incorreriam, igualmente, em certa forma de reducionismo, embora se tenha que admitir ter havido nesta corrente grande prudência a este respeito.

Finalmente, trataremos do problema do dualismo metodológico, de longa história e até hoje presente nas abordagens dialética e hermenêutica em ciências sociais. No século passado as distinções entre ciências da natureza e ciências do espírito ou da cultura (Natur-, Geistes- eKulturwissenschaften), ciências nomotéticas e ideográficas, marcaram o início da concepção dualista em epistemologia (diferenças de conhecimento), metodologia (diferenças de métodos) e ontologia (diferenças quanto à natureza dos objetos). Embora Weber tenha se esforçado por estabelecer um diálogo entre as duas posturas, na sua caracterização da natureza das ciências sociais, foi pouco valorizado por certos interpretes do seu pensamento. Habermas inicia sua Lógica das ciências sociais com clara defesa do dualismo em seus três aspectos. Em Adorno, em todo o denominado marxismo ocidental (a expressão foi utilizada por Merleau-Ponty em As aventuras da dialética e posteriormente consagrada) e na sociologia compreensiva em geral, o dualismo tem preservado às ciências da natureza o campo das concepções empiristas e positivistas. Popper e os pós-popperianos desenvolveram fortes argumentos contra estas estranhas concessões metodológicas. $O$ dualismo, muitas vezes, pode facilitar certos reducionismos. Outra dificuldade que apresenta é não possibilitar interação com as metodologias das ciências naturais de modo adequado, através do diálogo crítico. Quanto às ciências formais, lógica e matemática, e sua rica metodologia, nada se declara nesta postura, como se os autores desconhecessem, por exemplo, a própria lógica formal como gramática profunda do seu discurso. Acaba-se estranhamente por defender um discurso sem estrutura sintática ou argumentativa. Marcuse é dos mais tentados a este percurso.

As regras metodológicas nos fornecem critérios para a avaliaçáo dos procedimentos científicos. Uma regra não é verdadeira ou falsa. As regras são convenções do jogo da ciência. Não adotamos regras isoladamente, mas conjuntos de regras. Rejeitamos regras isoladas e até conjuntos de regras, e em alguns casos, introduzimos novas regras em um conjunto que as rejeita ou se altera para recebêlas. As regras estão organizadas de acordo com seu nível de generalidade, suas relaçóes com as outras regras do sistema e grau de utilidade na avaliação das 
atividades de pesquisa. Como não existem ações humanas fora de um campo normativo, as atividades de investigação respeitam padróes com maior ou menor permanência e intensidade. A permanência refere-se à duração de uma regra, sendo todas elas finitas, o que confere grande importância metodológica à história da ciência. Há critérios não metodológicos que influenciam na adoção de regras metodológicas, objeto de investigação da sociologia da ciência; e o seu peso dependerá de estudos de caso, sendo impossível legislar sobre isto de modo a priori. Tampouco existem regras para a adoção de regras metodológicas. Regras são apostas que podem ser avaliadas exclusivamente pelo critério pragmático: as consequiências práticas da adoção de um sistema de regras nos dizem a respeito de sua propriedade e adequaçáo, isto é, reconstroem o desenvolvimento científico e operam prospectivamente o seu modo constitutivo, influenciando a adoção de métodos, teorias e esquemas conceituais e estratégias metateóricas de investigação. As duas funções principais das regras metodológicas são, portanto, a reconstrutiva e a constitutiva, funçóes passiva e ativa, a abordagem da estrutura da atividade científica e a abordagem dinâmica dọs processos de investigação. $\mathrm{A}$ sintaxe e a semântica fornecerão instrumentos ricos de reconstrução metodológica e a pragmática nos auxiliará na caracterização da ciência enquanto atividade; a ciência como linguagem estruturada e a ciência como forma de ação social.

Se fôssemos tratar aqui da natureza do instrumental de fundamentação necessário para se gerar reconstruções metodológicas, teríamos que levar em consideração distinções conceituais tanto de origem científica quanto filosófica. Esta é a razão da metodologia como disciplina metacientífica ser dificilmente enquadrada exclusivamente na ciência ou na filosofia, o que é facilmente apreendido bastando para isso listar os termos de maior uso em qualquer corrente, como por exemplo, conceito, sentença, proposição, enunciado, sentido, argumento, verdade, essência, contradição, interpretação, explicação, teoria, existência. A metodologia é uma disciplina que possui duplo estatuto. A epistemologia, a metafísica, e até a ética e a estética, a lógica formal silogística ou matemática, a sociologia, a antropologia, a cibernética, a informática, a teoria dos sistemas, a teoria das decisóes, a semântica teórica, a filologia, a estilística, a lingüística e a semiótica fornecem instrumentos conceituais para a reflexão metodológica, conforme as preferências intelectuais de cada autor, escola, enfoque, tradição. Há sempre usos seletivos em amplo repertório conceitual de época disponível disputando os investigadores.

É o caráter normativo da metodologia, revelado pelas regras metodológicas, que legislam sobre a extensão representada pelos termos e proposiçōes científicas, ou, de modo mais amplo, a respeito do processo de investigação compreendido pelos sistemas tecnológicos (métodos e técnicas de pesquisa social empírica), teóricos (esquemas conceituais, tipologias, leis ou generalizações) e metateóricos (âmbito das reconstruçóes metodológicas). Neste último nível do conhecimento 
em ciências sociais são enunciadas as regras que permitem estabelecer os critérios com base nos quais se decide entre tecnologias de pesquisa, teorias, esquemas conceituais e fundamentos alternativos proporcionados por repertório de época. $\mathrm{E}$ a prática da pesquisa encarrega-se de ampliar este estoque de informaçóes depositado na história da ciência para uso seletivo contemporâneo e futuro. Há, entretanto, decisóes normativas localizadas em cada um dos níveis do conhecimento, mas são de natureza menos abstrata e circunstanciada. Alguns autores limitam a metodologia a um destes âmbitos regionais, como, por exemplo, os adeptos do empirismo e do operacionalismo sociológicos ao reduzir a nossa disciplina ao enunciado de procedimentos operacionais, quantitativos ou qualitativos, de coleta e tratamento de dados; os estudos e decisões de fundamentação ironicamente abandonados aos filósofos epistemólogos. Uma estranha delegação que significativa parte dos filósofos tem gentilmente dispensado.

Na solução reducionista teríamos um único conjunto de regras metodológicas para as chamadas ciências empíricas. A avaliação das ciências sociais por estes critérios tende a ser a da rigidez que uma vasta literatura tem demonstrado, as diferenças de grau e não de natureza sendo enfatizadas ou, o que resulta mais grave, a desqualificação de sua pretensão de atingir conhecimento empírico e científico da vida social. As infrutíferas tentativas de construir o catálogo dos enunciados empíricos, das proposiçóes protocolares da sociologia e das ciências do comportamento em geral, atestam as dificuldades deste projeto. Alguns autores são mais flexíveis na defesa da unidade metodológica das ciências empíricas, como Popper, que ao tratar das açóes humanas rompe critérios duros de demarcação entre filosofia social e sociologia, admitindo algumas regras metodológicas diferenciadas como, por exemplo, o individualismo metodológico e a lógica situacional.

A posição dos dualistas não será menos complicada. Abandonam as ciências da natureza às concepçóes empiristas e positivistas, restringindo seus enunciados metodológicos, explicitamente críticos das posturas mencionadas, a características que distinguem e isolam as ciências sociais das demais ciências. Posteriormente, são obrigados a reorientar suas reflexóes, como o faz Habermas, como condição para não inviabilizar os diálogos críticos interdisciplinares entre as próprias ciências sociais. Não faltará quem sustente posição suspeitosa frente à incorporação de informações de outras disciplinas científicas ao acervo dos cientistas sociais, incorporação de longa tradição, de caráter metafórico ou literal.

Se os reducionistas contribuíram para o desenvolvimento dos procedimentos empíricos de investigação, enfraquecendo as posiçóes estritamente reflexivas, os dualistas fortaleceram o estudo da identidade metodológica das ciências sociais fertilizando inúmeras áreas de investigação, principalmente as que exigem abordagens qualitativas. Entretanto, a metodologia das ciências sociais muito 
perdeu pela falta de contatos com as metodologias das ciências formais (lógica e matemática) e naturais.

Somente a consideração das regras metodológicas de um ponto de vista pluralista respeitará a riqueza da interação entre as ciências, que a história registra. As ciências empíricas naturais, as ciências sociais e as ciências formais possuem regras metodológicas diferenciadas e comuns; características de técnicas e de métodos e características lógicas e epistemológicas que se manifestam na construção e teste das teorias e na geração das diferentes formas de explicação científica, causais e teleológicas. Em suma, teremos de investigar as normas que orientam e padronizam os procedimentos de investigação das três, duas ou uma única das famílias de ciências. Se, como consequiência, o programa de uma única metodologia é suspeito e inadequado, na sua forma reducionista ou dualista, o pluralismo na consideração das regras deverá se pautar por extrema prudência para não descambar no ecletismo de roupagem metodológica. Para evitar esta dificuldade é preciso especificar dois sentidos do termo pluralismo. O pluralismo interno a uma teoria da ciência, que pode coincidir com certos reducionismos atenuados não relativistas, admite algumas regras metodológicas especificas a um conjunto de ciências sem incompatibilidade entre elas. É o caso, anteriormente mencionado, da metodologia popperiana das ciências sociais.

Pode-se classificar as reconstruções metodológicas de processos de investigação social pela natureza do instrumental de reconstrução utilizado, distinçóes conceituais de disciplinas filosóficas ou científicas que, retiradas dos seus contextos de origem, passam a exercer funções de fundamentação de estratégias de investigação e se organizam em esquemas-base metateóricos: reconstruções metodológicas de fundamentação analítica, reconstruçóes metodológicas de fundamentação hermenêutica, reconstruçóes metodológicas de fundamentação dialética e reconstruçóes pluralistas, que combinam de alguma forma distinções conceituais e regras metodológicas geradas em várias correntes destas famílias metodológicas. Este pluralismo externo evitará os perigos do ecletismo metodológico pela incorporação crítica de novas contribuiçōes a uma postura teórica e metodológica inicial que, em constantes reelaborações, fruto de intenso diálogo, determinará os caminhos, decisóes e apostas intelectuais. Como o programa de Habermas hoje exemplifica, o pluralismo neste segundo sentido, pode ser compatibilizado com formas atenuadas de dualismo metodológico.

José Jeremias de Oliveira Filho é professor do Departamento de Sociologia da Faculdade de Filosofia, Letras e Ciências Humanas da USP. 